\title{
An unusual cause of recurrent pancreatitis: Duodenal duplication cyst
}

\author{
Rameeta J Lad MD FRCPC ${ }^{1}$, Peter Fitzgerald MD FRCS ${ }^{2}$, Kevan Jacobson MBBch FRCP ${ }^{3}$
}

\begin{abstract}
RJ Lad, P Fitzgerald, K Jacobson. An unusual cause of recurrent pancreatitis: Duodenal duplication cyst. Can J Gastroenterol 2000;14(4):341-345. Intestinal duplications are rare anomalies that usually present in childhood. Of these, duodenal duplications are among the most uncommon. Although these usually present with obstructive symptoms or bleeding, pancreatitis may occur. A case of duodenal duplication cyst causing recurrent pancreatitis in a 12-year-old girl is presented. The literature on duodenal duplications, and their epidemiology, embryology and pathophysiology is reviewed
\end{abstract}

Key Words: Duodenal duplications; Intestinal duplications; Pancreatitis

\section{Cause inhabituelle de pancréatite récidivante :} kyste de duplication duodénale

RÉSUMÉ : Les duplications intestinales sont des anomalies peu fréquentes qui se rencontrent surtout chez les enfants, et les duplications duodénales figurent parmi les plus rares. Bien que ces anomalies produisent généralement des symptômes d'obstruction et des saignements, elles peuvent aussi se manifester par des pancréatites. Voici le cas d'une jeune fille de 12 ans souffrant d'une pancréatite récidivante, secondaire à un kyste de duplication duodénale. L'article passe en revue la documentation scientifique sur la duplication duodénale, son épidémiologie, son embryologie et sa physiopathologie.
$\mathrm{P}$ ancreatitis is a relatively uncommon condition in pediatric patients. The diagnosis may be difficult because of nonspecific symptomatology. Once the diagnosis is confirmed, a thorough evaluation is needed to determine the etiology in this age group. Recurrent pancreatitis often remains undiagnosed for many years, and congenital anomalies are one possible cause. We present a case of a child with recurrent pancreatitis secondary to a duodenal duplication cyst in the second part of the duodenum.

\section{CASE PRESENTATION}

A previously healthy 11-year-old girl presented with a 10 day history of crampy epigastric pain, nausea and vomiting. She was taking no medications and had no exposure to toxins. Her father had had hypertriglyceridemia-induced pancreatitis at age 28 years. At the time of presentation, examination revealed epigastric tenderness but no perito- neal signs. Amylase level was $612 \mathrm{U} / \mathrm{L}$, aspartate amino transferase (AST) $335 \mathrm{U} / \mathrm{L}$, alanine aminotransferase 199 $\mathrm{U} / \mathrm{L}$, total bilirubin $15 \mu \mathrm{mol} / \mathrm{L}$ and direct bilirubin 12 $\mu \mathrm{mol} / \mathrm{L}$. Ultrasound revealed a diffusely swollen pancreas consistent with pancreatitis, but no abnormalities of the hepatobiliary system were evident. Computed tomography (CT) of the abdomen revealed multiple cystic areas throughout the neck and body of the pancreas consistent with pancreatitis. The patient improved with conservative management and was discharged. Subsequent calcium and triglyceride levels were normal.

One year later, she again presented with severe epigastric pain associated with nausea and vomiting. On examination she was afebrile and hemodynamically stable, and had mild epigastric tenderness with no palpable masses. Hemoglobin, leukocyte count, electrolytes, glucose and calcium were normal. Amylase level was $2238 \mathrm{U} / \mathrm{L}$, AST $23 \mathrm{U} / \mathrm{L}$, alkaline

Divisions of ${ }^{1}$ Gastroenterology, ${ }^{2}$ Pediatric Surgery, and ${ }^{3}$ Pediatrics, Children's Hospital, Hamilton Health Sciences Corporation, Hamilton, Ontario

Correspondence and reprints: Dr Kevan Jacobson, BC Children's Hospital, Division of Gastroenterology, Room D615A, 4480 Oak Street,

Vancouver, British Columbia V6H 3V4. Telephone 604-875-2332, fax 604-875-3244, e-mail kjacobson@cw.bc.ca

Received for publication April 1, 1999. Accepted July 29, 1999 


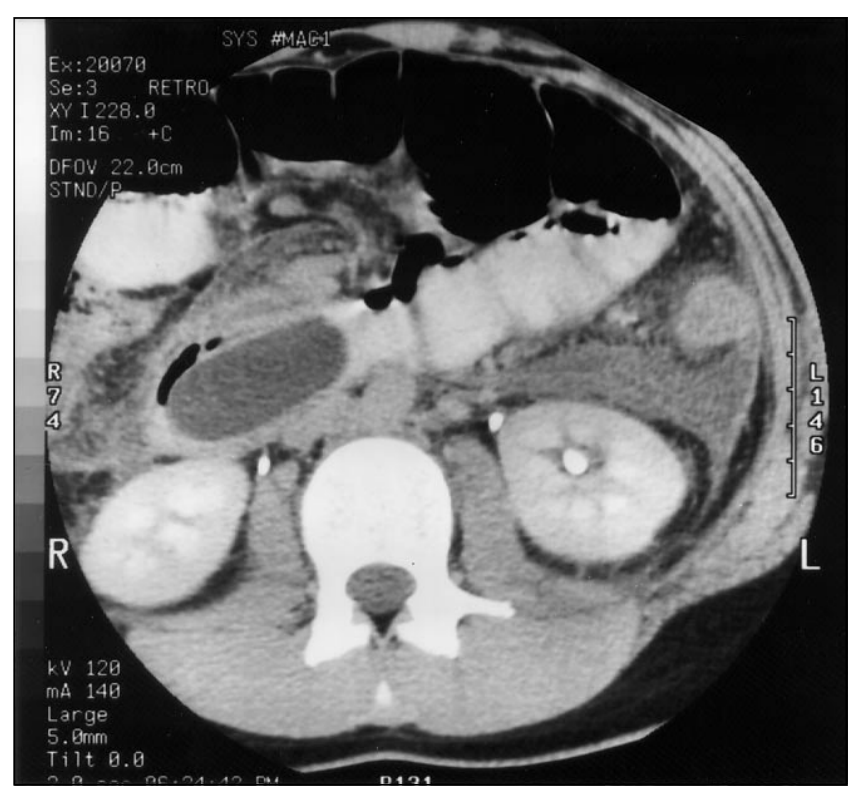

Figure 1) Computed tomographic scan of the abdomen showing large cystic structure in the vicinity of the second part of the duodenum and the uncinate process of the pancreas. This was initially thought to be intrapancreatic and was associated with necrotizing pancreatitis

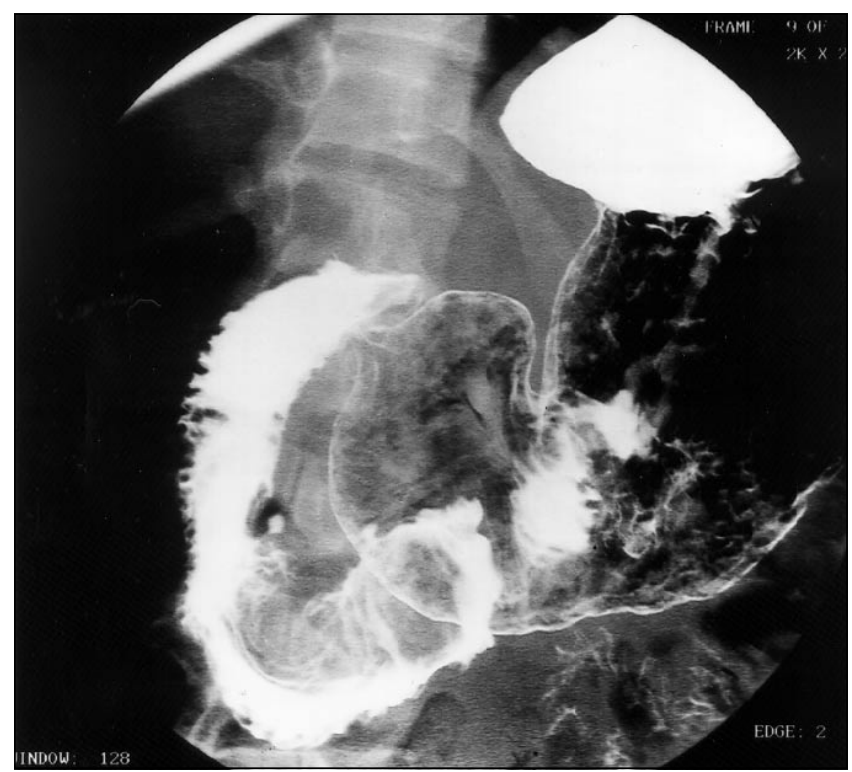

Figure 2) Upper gastrointestinal series showing an intraluminal polypoid lesion arising from the medial wall of the second part of the duodenum

phosphatase $162 \mathrm{U} / \mathrm{L}$, gamma-glutamyl transferase $36 \mathrm{U} / \mathrm{L}$ and total bilirubin $14 \mu \mathrm{mol} / \mathrm{L}$. She was admitted with acute pancreatitis, and placed on intravenous fluids and bowel rest. Ultrasound of the abdomen revealed an edematous pancreas with a cystic lesion near the head. The patient subsequently developed hypocalcemia and hyperglycemia, which were treated. CT of the abdomen showed extensive swelling and lack of enhancement of the body of the pancreas, and a $3 \times 3 \times 4 \mathrm{~cm}$ cystic lesion near the uncinate process (Figure 1 ). She was placed on total parenteral nutrition, with gradual improvement in symptoms and laboratory parameters.

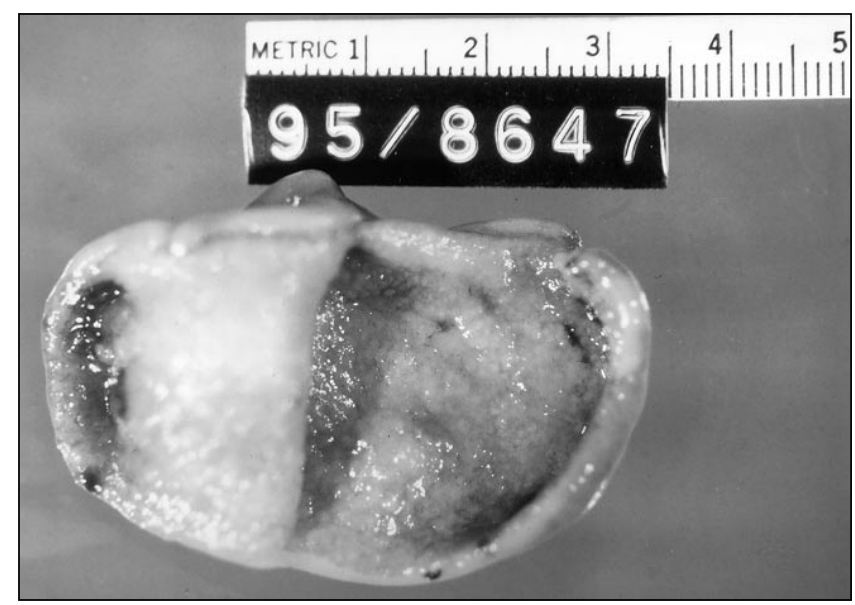

Figure 3) Resected cystic duodenal duplication, with inside lining exposed

One month after recovery, she underwent endoscopic retrograde cholangiopancreatography (ERCP), which revealed a pedunculated polypoid lesion arising in the vicinity of the major papilla. Upper gastrointestinal series confirmed a large polypoid lesion arising in the second part of the duodenum (Figure 2). The polypoid lesion appeared to have prolapsed into the third and fourth part of the duodenum, causing traction on the second part of the duodenum. She went on to have an intraoperative esophagoduodenoscopy with a view to attempt to snare the polypoid structure. Due to the broad-based nature of the stalk, this was not attempted and she required a laparotomy with duodenotomy. At surgery, the large cystic duplication was found arising $5 \mathrm{~mm}$ distal to the papilla of Vater and was successfully resected. Macroscopically, the structure measured $3.7 \times 2.8 \times 0.8 \mathrm{~cm}$, was cystic and was lined on both sides with mucosa that looked identical to the surrounding duodenal mucosa (Figure 3). On histological examination, the lesion consisted of small bowel mucosa with Brunner's glands and some pancreatic acini and ducts, consistent with a duodenal duplication cyst.

\section{DISCUSSION}

Acute pancreatitis is an uncommon cause of abdominal pain in children. The most frequent etiologies are trauma, drugs and viral infections (1). Recurrent pancreatitis is infrequent in the pediatric population, and the etiology is often unclear. It is, however, important to rule out congenital anomalies of the pancreatobiliary tree such as choledochal cyst, choledochocele, anomalous insertion of the common bile duct, stenosis of the ampulla of Vater, pancreatic duct aplasia, annular pancreas and pancreas divisum. In older children and adolescents, gallstones may cause pancreatitis. Even rarer are intraluminal duodenal diverticuli and gastroduodenal duplication cysts $(2,3)$.

Enteric duplications are spherical or tubular structures containing mucosa and a smooth muscle layer. They occur anywhere in the alimentary tract, with the ileum being the most common site (4). Duodenal duplication cysts are rare, 
TABLE 1

Review of duodenal duplications causing pancreatitis

\begin{tabular}{|c|c|c|c|c|c|c|c|}
\hline Author, year (reference) & Sex & $\begin{array}{l}\text { Age at } \\
\text { diagnosis } \\
\text { (years) }\end{array}$ & Diagnostic tests & Operative procedures & Location & $\begin{array}{l}\text { Diameter } \\
(\mathrm{cm})\end{array}$ & Communication \\
\hline $\begin{array}{l}\text { Williams and Hendren, } 1971 \\
\text { (19) }\end{array}$ & M & 7 & $\begin{array}{l}\text { ivC, intraoperative } \\
\text { pancreatogram }\end{array}$ & $\begin{array}{l}\text { Laparotomy, } \\
\text { pancreatoduodenectomy }\end{array}$ & Intrapancreatic & 1.5 & None \\
\hline Jones et al, 1982 (14) & $\mathrm{F}$ & 28 & ivC, UGIS, ERCP & Duodenotomy, excision & Intraluminal & 3 & CBD \\
\hline Shimada et al,1983 (31) & $\mathrm{F}$ & 49 & UGIS & $\begin{array}{c}\text { Laparotomy, } \\
\text { hemigastrectomy, partial } \\
\text { excision of pancreatic head }\end{array}$ & Intraluminal & 6 & APD \\
\hline Abrams and Connon, 1984 (15) & M & 37 & US, UGIS, ERCP & Duodenotomy, excision & Intraluminal & 2 & None \\
\hline Bulajic et al, 1991 (26) & $\mathrm{F}$ & 23 & EGD, US, ERCP & Duodenotomy, excision & Intraluminal & $4 \times 8$ & None \\
\hline Traif and Khan, 1992 (34) & M & 11 & US, CT, UGIS & Endoscopic drainage & Intraluminal & - & - \\
\hline Okuyama et al, 1992 (33) & $\mathrm{F}$ & 1 & $\mathrm{CT}$ & $\begin{array}{l}\text { Laparotomy, intraoperative } \\
\text { pancreatography }\end{array}$ & Intrapancreatic & 1.5 & PD \\
\hline Lang et al, 1994 (35) & M & 4.5 & UGIS, CT, ERCP & Endoscopic drainage & Intraluminal & 2.8 & PD \\
\hline
\end{tabular}

APD Accessory pancreatic duct; CBD Common bile duct; CT Computed tomography; EGD Esophagogastroduodenoscopy; ERCP Endoscopic retrograde cholangiopancreatography; F Female; ivC Intravenous cholangiogram; M Male; UGIS Upper gastrointestinal series; US UItrasound; PD Pancreatic duct

accounting for only $5 \%$ of all intestinal duplications (4-6). There are a number of theories to explain the pathogenesis of these lesions. McLetchie et al (7) proposed the earliest theory in 1954. During the third week of gestation, the notochord fuses with the embryonic endoderm to form notochordal plates. If adhesions persist during separation of the notochord and endoderm in the fourth week, duplication cysts can occur. This is concordant with the association between vertebral defects and duodenal duplications extending into the mediastinum (7-9). The most widely accepted theory of the pathogenesis of gastrointestinal duplication is that of Bremer (10). He suggested that the intestinal lumen is occluded by the rapid proliferation of epithelial cells in the embryo at the sixth or seventh week of gestation, a time at which the intestinal tract undergoes a rapid increase in length. Epithelial cells normally secrete a fluid, which results in the formation of vacuoles that coalesce to form a lumen. Duplication formation results from failure of these vacuoles to coalesce into one single channel. Any portion that forms separate from the main gastrointestinal tract develops into normal tissue but is separate from it. The vascular theory of pathogenesis proposed by Favara et al (11) notes the association of enteric duplications with intestinal atresia. Enteric duplications are proposed to occur as a result of intrauterine intestinal ischemia, which results in necrosis of a portion of bowel, with focal sparing of segments that derive nutrition from adjacent inflammatory tissue (11).
There are over 80 reported cases of duodenal duplication in the English literature. In one review, over $75 \%$ of patients were diagnosed before the age of 16 years (12); however, a number of cases have been reported in adults (12-16). Duplications may be clinically silent for years before presentation. Johanson et al (16) reported a 62-year-old man who presented with epigastric pain secondary to duplication. The duplications are usually cystic structures anywhere from 2 to $12 \mathrm{~cm}$ in diameter arising intralumenally or extralumenally, and may share one wall with the duodenum $(15,17,18)$. Rarely, they may be intrapancreatic or intrahepatic $(19,20)$. Although single duplications are the most common by far, multiple duplications such as combined duodenal and gastric or ileal can occur $(21,22)$. The cysts are usually filled with clear fluid but may contain gallstones (23), bile (24) or pancreatic fluid if they communicate with the biliary or pancreatic system. Both the pancreatic and common bile duct may open into the cyst $(14,16,25)$ or may drain solely via the ampulla of Vater, as in the present case. Communication may occur with the lumen of the duodenum via a separate orifice within the cyst (26). The blood supply is intimately associated with that of the duodenum so that surgical dissection of the duplication may be difficult. Microscopically, duplications consist of a smooth muscle layer covered by duodenal mucosa on both sides. Nests of ectopic pancreatic tissue may be present (22), and islands of gastric mucosa are seen in up to $13 \%$ of duplication cysts, as was seen in this case $(25,27)$. 
Presentation is variable and includes symptoms of obstruction, bleeding or pancreatitis. Duodenal obstruction occurs secondary to the cyst obstructing the lumen and presents similar to gastric outlet obstruction with abdominal pain, nausea and vomiting. Bleeding results from peptic ulceration of mucosa within the cyst or in adjacent bowel, from pressure necrosis of the expanding cyst on the small bowel lumen or secondary to intussusception with the cyst acting as a lead point (28). Because some cysts contain gastric mucosa, peptic ulceration and rarely perforation have been reported $(17,29)$.

There are 12 reported cases in the English literature of duodenal duplication cysts presenting as pancreatitis $(14,15,19,26)$. The age of diagnosis may range from infancy to adulthood (Table 1). Three cases were secondary to intrapancreatic duodenal duplications $(19,30,33)$, and only nine were secondary to intraluminal duodenal diverticuli. Our case is another example of pancreatitis secondary to intraluminal duodenal duplication. The mechanism of pancreatitis in these cases is related to the mobile cyst obstructing the pancreatic duct. Communication between the cyst and pancreatobiliary ductal system is common. In our case, the duodenal duplication cyst caused intermittent obstruction of the pancreatic duct because of its proximity to it. In addition, traction on the cyst would cause intermittent obstruction of the ampulla. It is interesting to note that CT scan of the abdomen one year earlier showed no evidence of a single intraluminal cyst but multiple pancreatic cysts consistent with pancreatitis. This highlights the high degree of suspicion needed to make the diagnosis and the diagnostic importance of ancillary tests such as upper gastrointestinal series and upper gastrointestinal endoscopy. In addition, despite the size

\section{REFERENCES}

1. Lerner A, Branski D, Lebenthal E. Pancreatic diseases in children. Pediatr Clin North Am 1996;43:125-56.

2. Hartley RH, Barlow AP, Kilby JO. Intraluminal duodenal diverticulum: an unusual cause of acute pancreatitis. Br J Surg 1993;80:488.

3. Finnie IA, Ghosh P, Garvey C, Poston GJ, Rhodes JM. Intraluminal duodenal diverticulum causing recurrent pancreatitis: treatment by endoscopic incision. Gut 1994;35:557-9.

4. Bower RJ, Sieber WK, Kiesewetter WB. Alimentary tract duplications in children. Ann Surg 1978;188:669-74.

5. Soper RT, Selke AC. Duplication cyst of the duodenum: case report and discussion. Surgery 1970;68:562-6.

6. Dahn K, Poulsen O. Enterocystomas: a report of 6 cases. Acta Chir Scand 1951;102:21.

7. McLetchie NG, Purves KJ, Saunders RL. The genesis of gastric and certain intestinal diverticula and enterogenous cysts. Surg Gynecol Obstet 1954;99:135.

8. Sonoda N, Takaya J, Okamoto K, et al. Transdiaphragmatic duodenal duplication in a premature infant. J Pediatr Surg 1987;22:372-3.

9. Dénes J, HontiJ, Léb J. Dorsal herniation of the gut: a rare manifestation of the split notochord syndrome. J Pediatr Surg 1967;2:359.

10. Bremer JL. Diverticula and duplications of the intestinal tract. Arch Pathol 1944;38:144.

11. Favara BE, Franciosi RA, Akers DR. Enteric duplications, Thirty-seven cases: a vascular theory of pathogenesis. Am J Dis Child 1971;122:501-6.

12. Kirtley JA, Matsuka RA. Enterogenous cyst of the duodenum. Ann Surg 1957;145:265-8. of the cyst, the patient never had symptoms suggestive of proximal small bowel obstruction.

Clearly, duodenal duplication cysts are a rare cause of pancreatitis; however, the diagnosis should be considered in patients with recurrent pancreatitis with no attributable cause, especially in children. Upper gastrointestinal series, CT scan of the abdomen and ERCP are all useful investigations in the diagnosis of this condition. ERCP with cannulation of the common bile and pancreatic ducts should be attempted before surgical therapy because of the possible communication of these structures with the duplication cyst. In review of the literature, surgery has been the primary treatment in the past. A number of operations have been performed including local excision and cystojejunostomy. For cysts with a common wall with the duodenum aspiration, marsupialization, formation of a cystoduodenal window, resection and gastrojejunostomy have been performed (21). Complete excision is preferred if ectopic gastric mucosa is present but may be difficult if the cyst communicates with the pancreatobiliary tree. In our case the cyst was too large to snare and required surgical removal. Recently there have been three reports of endoscopy used to incise and drain these cysts $(16,34,35)$. Traif and Khan (34), and Lang et al (35) used a needle knife sphincterotome via duodenoscopes to incise and drain intraluminal duodenal duplication cysts causing recurrent pancreatitis. After two years of follow-up, the patients had no further attacks of pancreatitis. A similar procedure was done in a 62-year-old man by Johanson (16) with good results at 11 months' follow-up. In our patient, endoscopic incision and drainage would have been difficult because of the size of the lesion; however, surgical therapy has been definitive in this case.

13. Brooks B. Weinstein A. Cyst of the ampulla of Vater. Ann Surg 1943;117:728-33.

14. Jones PA, Rayter Z, Knight MJ, Rosswick RPR. Juxtampullary, bile-filled duodenal duplication cyst: another surgically correctable cause of acute pancreatitis. J R Soc Med 1982;75:662-4.

15. Abrams J, Connon JJ. Duodenal duplication presenting as relapsing pancreatitis in an adult. Am J Gastroenterol 1984;79:360-2.

16. Johanson JF, Geenen JE, Hogan W, Huibregtse K. Endoscopic therapy of aduodenal duplication cyst. Gastrointest Endosc 1992:38:60-3.

17. Dickinson WE, Weinberg SM, Vellios F. Perforating ulcer in a duodenal duplication. Am J Surg 1971;122:418-20.

18. Romero-Torres R. Duplication of the duodenum. Int Surg 1972;57:337-8.

19. Williams WH, Hendren WH. Intrapancreatic duodenal duplication causing pancreatitis in a child. Surgery 1971;69:708-15.

20. Imamoglu $\mathrm{KH}$, Walt AJ. Duplication of the duodenum extending into the liver. Am J Surg 1977;133:628-32.

21. Leenders EL. Treatment of duodenal duplication with international review. Am Surg 1970;36:368-71.

22. Inouye WY, Farrell C, Fitts WT, Tristan TA. Duodenal duplication: case report and literature review. Ann Surg 1965;162:910-6.

23. Luckmann KF, Welch RW, Schwesinger W, Oswalt C, Bannayan G. Symptomatic duodenal duplication cyst in an adult demonstrated by endoscopic retrograde cholangiopancreatography. Am J Gastroenterol 1979;72:153-9.

24. Thompson NW, Labow SS. Duplication of the duodenum in the adult. Arch Surg 1967;94:301-6.

25. Lavine JE, Harrision M, Heyman MB. Gastrointestinal duplications 
causing relapsing pancreatitis in children. Gastroenterology 1989;97:1556-8.

26. Bulajic M, Savic-Perisic M, Kornetti V, Colovic R, Milicevic M. Use of endoscopy to diagnose symptomatic duodenal duplication cyst in an adult. Endoscopy 1991;23:234-6.

27. Duque JJ, Strum WB, Kuster GGR, Kauffmann D. Upper gastrointestinal bleeding from a duodenal duplication: an unusual complication of a rare disease. Gastrointest Endosc 1989;35:471-2.

28. Feins NR, Nimbkar S. Duplications of the alimentary tract. In: Burrington JD, Kimura K, Schäfer JC, Witte JJ, eds. Abdominal Surgery of Infancy and Childhood. Luxembourg: Harwood Academic Publishers, 1996:39/1-15.

29. Knight CD, Allen MJ, Nagorney DM, Wold LE, DiMagno EP. Duodenal duplication cyst causing massive bleeding in an adult: an unusual complication of a duplication cyst of the digestive tract. Mayo Clin Proc 1985;60:772-5.

30. Scully RE, Mark EJ, McNeely BU. Case records of the
Massachusetts General Hospital. Case 48-1982. N Engl J Med 1982;307:1438-43.

31. Shimada H, Nakagawara G, Nakara A, et al. Duodenal duplication associated with pancreatic duct. Jpn J Surg 1983;14:320-6.

32. Stelling T, von Rooij WJJ, Tio TL, Reeders JWAJ, Bartelsman JJWM, Tytgat GNJ. Pancreatitis associated with congenital duodenal duplication cyst in an adult. Endoscopy 1987;19:171-3.

33. Okuyama, H, Matsuo Y, Fukui Y, Imura K, Kamata S, Okada A. Intrapancreatic duodenal duplication associated with pancreatic pseudocysts. J Pediatr Surg 1992;27:1573-4.

34. Traif IA, Khan MH. Endoscopic drainage of duodenal duplication cyst. Gastrointest Endosc 1992;38:64-5.

35. Lang T, Berquist W, Rich E, et al. Treatment of recurrent pancreatitis by endoscopic drainage of a duodenal duplication. J Pediatr Gastroenterol Nutr 1994;18:494-6.

36. Perrin RW. Communicating enterogenous cyst of duodenum receiving the termination of the common bile duct demonstrated by intravenous cholangiography. Radiology 1969;93:675-6. 


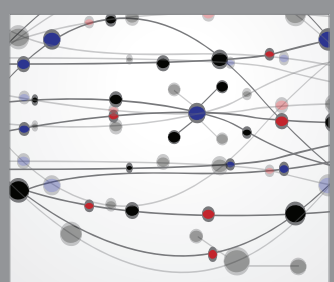

The Scientific World Journal
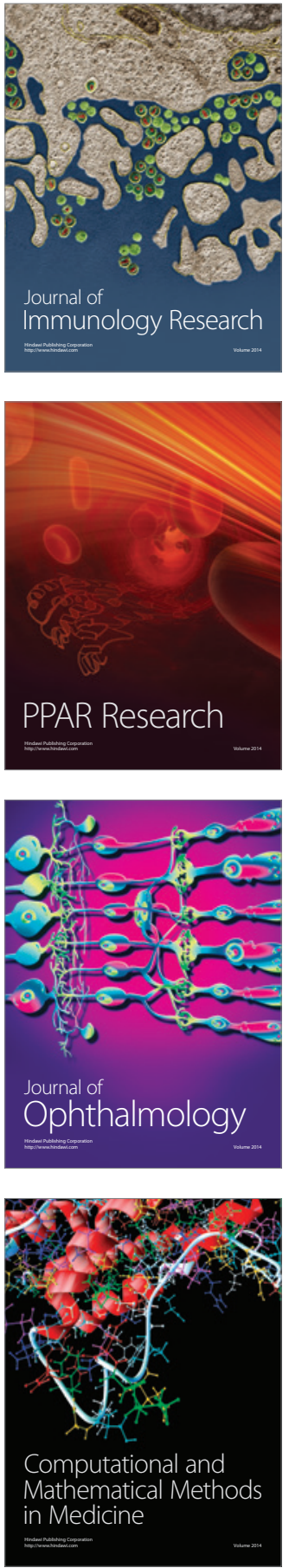

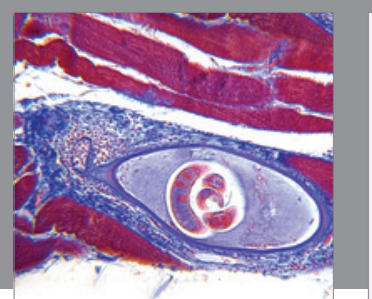

Gastroenterology Research and Practice

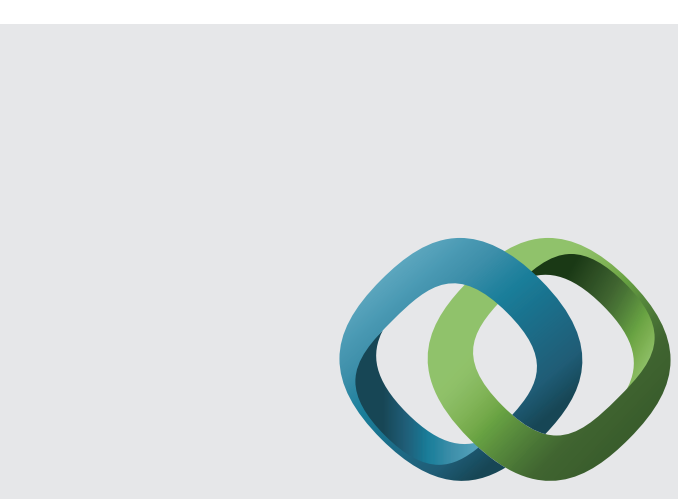

\section{Hindawi}

Submit your manuscripts at

http://www.hindawi.com
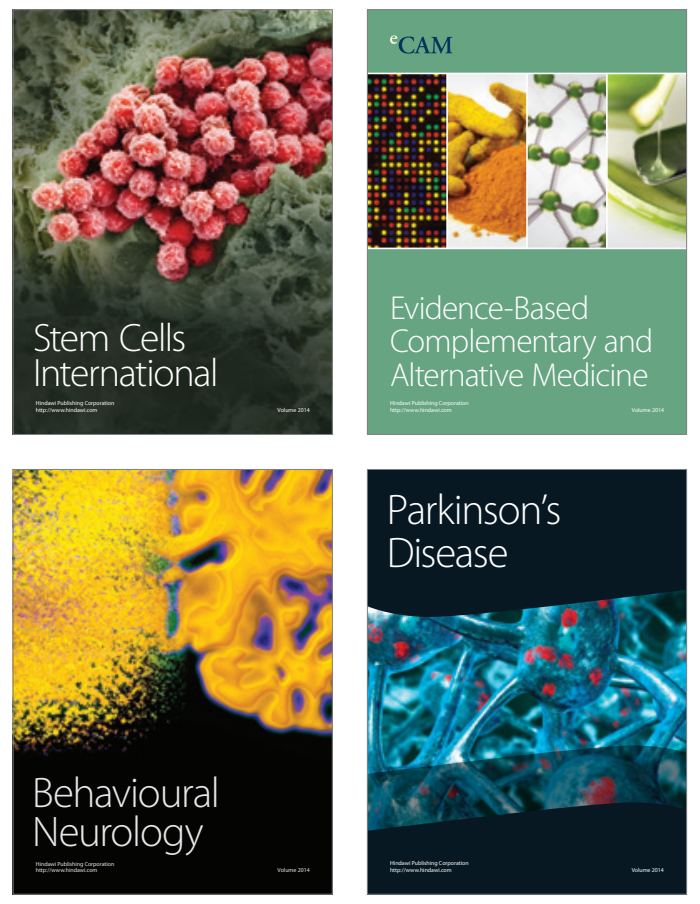
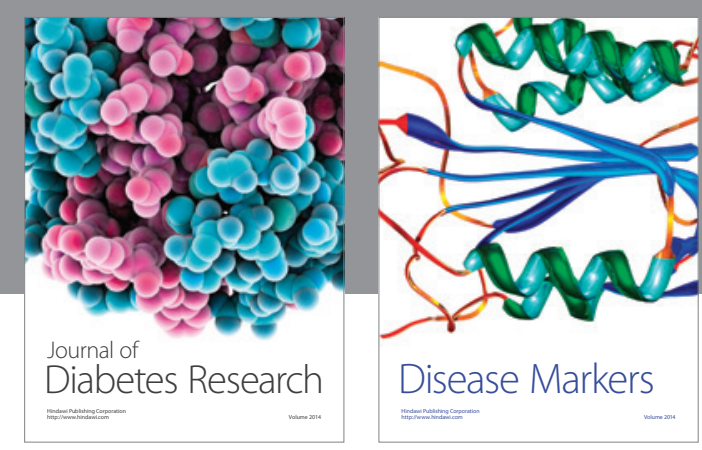

Disease Markers
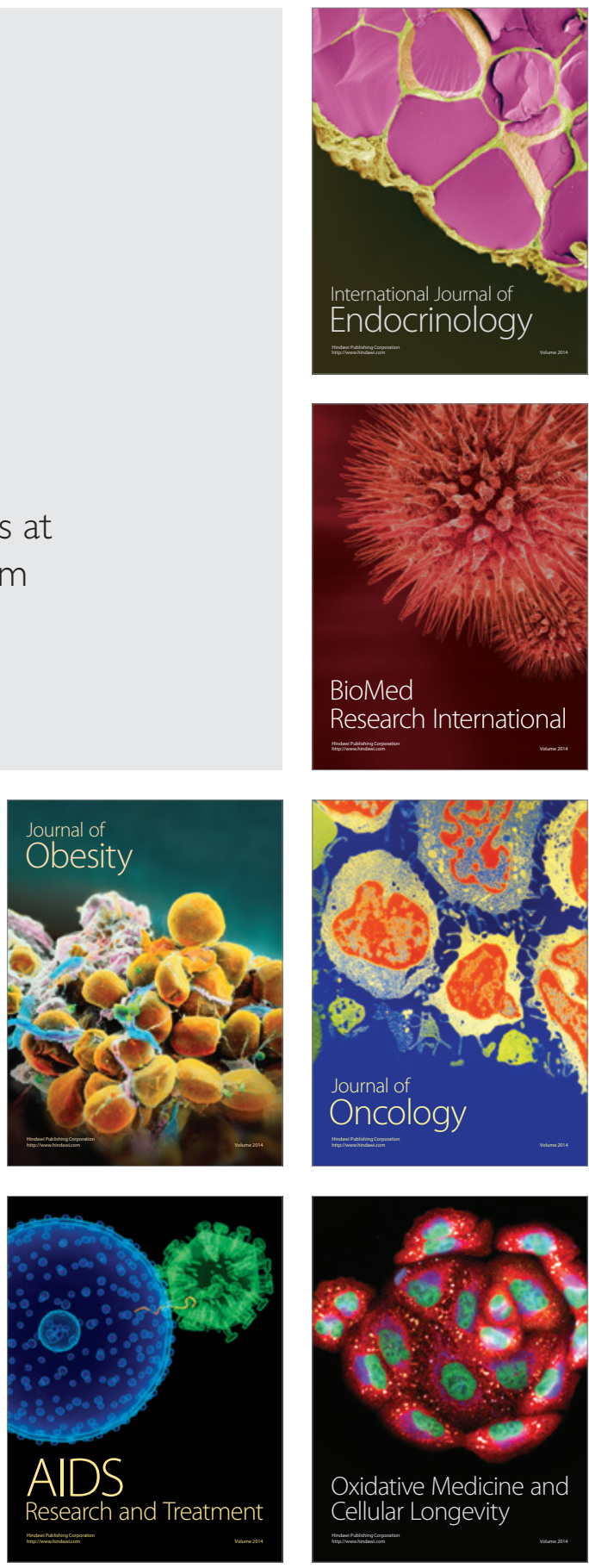